\title{
Artificial diet sandwich reveals subsocial behaviour in the coffee berry borer Hypothenemus hampei (Coleoptera: Curculionidae: Scolytinae)
}

\author{
F. E. Vega ${ }^{1}$, A. Simpkins ${ }^{1}$, M. M. Rodríguez-Soto ${ }^{2}$, F. Infante ${ }^{3}$ \& P. H. W. Biedermann ${ }^{4}$ \\ 1 Sustainable Perennial Crops Laboratory, U. S. Department of Agriculture, Agricultural Research Service, Beltsville, MD, USA \\ 2 Department of Crops and Agro-Environmental Sciences, University of Puerto Rico, Mayagüez, Puerto Rico \\ 3 El Colegio de la Frontera Sur (ECOSUR), Tapachula, Chiapas, México \\ 4 Research Group Insect Symbiosis, Max-Planck Institute for Chemical Ecology, Jena, Germany
}

\section{Keywords}

artificial rearing, bark beetles, broca del café, parental care, Scolytinae, social immunity

\section{Correspondence \\ Fernando E. Vega (corresponding author), Sustainable Perennial Crops Laboratory, U. S. Department of Agriculture, Agricultural Research Service, Bldg. 001, Beltsville, Maryland 20705, USA. E-mail: Fernando. Vega@ars.usda.gov}

Received: June 8, 2016; accepted: August 12, 2016.

doi: 10.1111/jen.12362

\begin{abstract}
An artificial diet sandwich, consisting of coffee berry borer artificial diet within two glass plates, has been developed to elucidate the behaviour of the coffee berry borer, an insect that in nature spends most of its life cycle inside the coffee berry. Various types of behaviour have been observed for the first time, including gallery construction, oviposition, gallery blocking, mating and most remarkably, subsocial tasks such as maternal sanitation and tending of eggs and larvae. This observational technique is a breakthrough for studies and manipulations of the coffee berry borer's social behaviour and could be applicable to other bark beetles, consequently yielding important insights into the origin of parental care in scolytine beetles.
\end{abstract}

\section{Introduction}

The coffee berry borer (Hypothenemus hampei (Ferrari); Coleoptera: Curculionidae, Scolytinae) is the most devastating insect pest of coffee and has invaded most coffee-producing countries (Vega et al. 2015). Damage begins after a colonizing female enters the coffee berry and oviposits within tunnel systems (=galleries) bored throughout the two seeds inside the berry. Upon hatching, larvae feed on the seeds, thus reducing yields and quality of the marketable product. There is sibling mating inside the berry, and when conditions are favourable, inseminated adult females leave the berry in search of a coffee berry to colonize (Vega et al. 2015). The insect spends most of its life cycle hidden inside the coffee berry, making it impossible to observe its behaviour under natural conditions. A similar situation occurs with bark beetles that live in the phloem of trees, but a technique based on what is known as phloem sandwiches, consisting of placement of phloem between two glass or plastic plates, has been successfully used to study their behaviour (Bedard 1933; Hopping 1961; Beanlands 1966; Kinn and Miller 1981; Salom et al. 1986; Grosman et al. 1992; Taylor et al. 1992; Aflitto et al. 2014).

Some of the different types of behaviour observed in scolytine beetles, despite species using different substrates ranging from phloem and xylem of woody plants, to herbs and seeds, includes excavation of oviposition tunnels, protection from microorganisms, tending of larvae and shovelling of frass (Kirkendall et al. 1997, 2015). Behavioural observations of individuals within their tunnels, however, are restricted to species that can be reared in artificial diet, like phloem and xylem breeding bark and ambrosia beetles (Cardoza et al. 2006; Biedermann et al. 2009). 
Some studies have revealed division of labour and social structures from subsociality (=parental care) to eusociality (Biedermann and Taborsky 2011; Kirkendall et al. 2015). Scolytine beetles breeding on seeds, such as the coffee berry borer (Vega et al. 2015) and Coccotrypes spp. (Herfs 1950, 1959; Ueda 1997), are known to live gregariously in their galleries, with adults and offspring of different age present at the same time, but their behaviour has not been studied so far, with the exception of the mating behaviour of the coffee berry borer (Silva et al. 2012).

To learn more about the behaviour of the coffee berry borer, we have developed a technique involving the placement of coffee berry borer artificial diet within two glass plates, henceforth referred to as artificial diet sandwiches. In this study, we present the technique and describe various types of social behaviour exhibited by adult female coffee berry borers.
This study serves as a preamble to future studies aimed at elucidating the behaviour of the insect in more detail.

\section{Materials and Methods}

The first step in the development of the artificial diet sandwich was to obtain coffee berry borer diet discs that could be placed between two glass plates. In the laminar flow hood, ca. $0.3 \mathrm{ml}$ of sterile coffee berry borer artificial diet (Vega et al. 2011) was placed in repeated rows on a $25.4 \times 22.9 \mathrm{~cm}$ glass plate (fig. la). A second glass plate was placed over the diet, resulting in rows of flattened semicircular diet discs. Four to five rows, resulting in 20-30 discs (depending on spacing), can be placed on one $25.4 \times 22.9 \mathrm{~cm}$ glass plate (fig. la). The two glass plates were placed inside a plastic bag, which was is in turn placed for
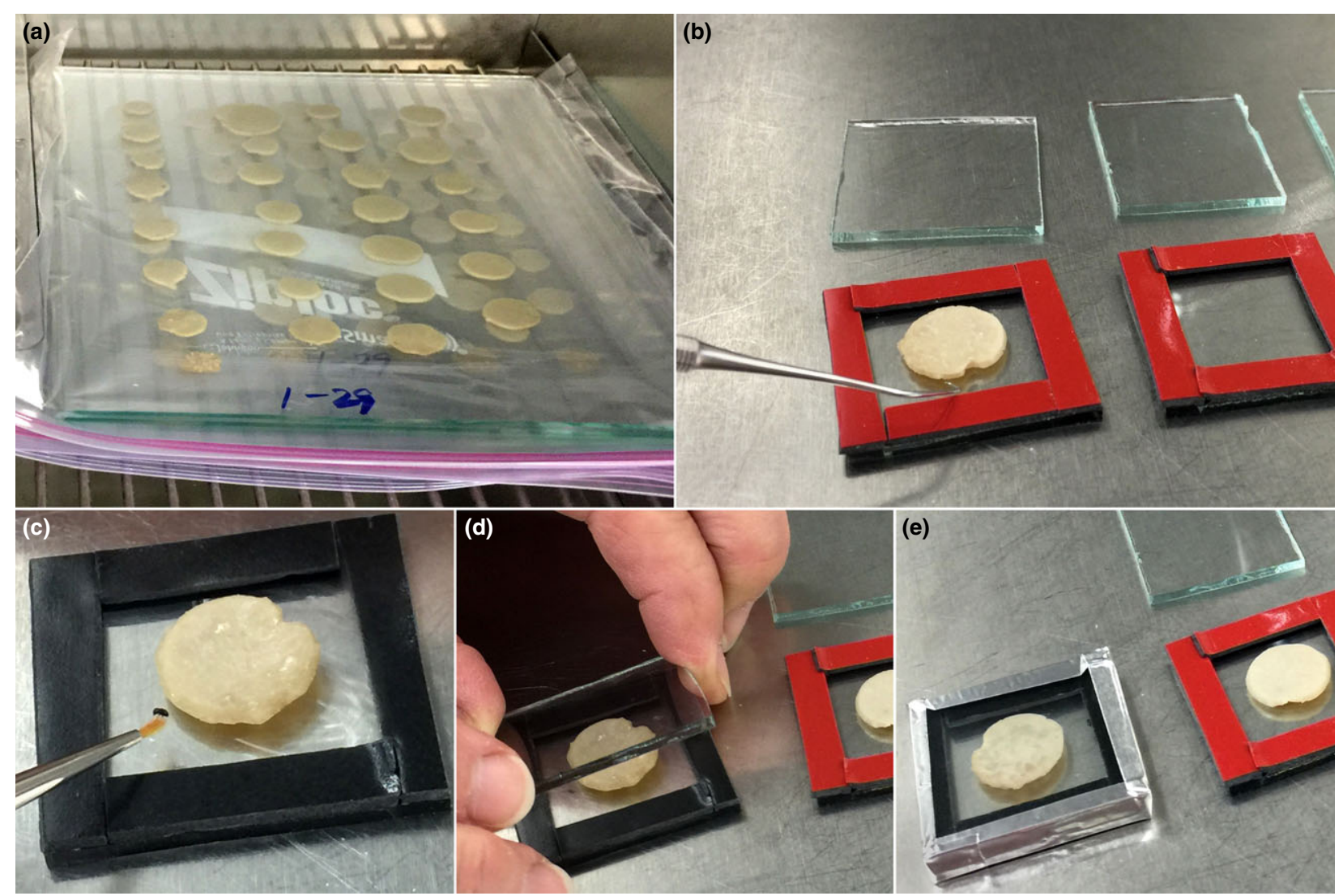

Fig. 1 Preparation of coffee berry borer artificial diet sandwiches: (a) Approximately $0.3 \mathrm{ml}$ of sterile coffee berry borer artificial diet was placed in repeated rows on a $25.4 \times 22.9 \mathrm{~cm}$ glass plate and a second glass plate was placed over the diet, resulting in rows of flattened semicircular diet discs. The two glass plates were placed inside a plastic bag, which was is in turn placed for 5-6 days inside an oven set at $27^{\circ} \mathrm{C}$. (b) A 1-mm-thick strip of double-sided Scotch ${ }^{\circledR}$ Extreme Mounting Tape is adhered to the perimeter of a $3.8 \times 3.8 \mathrm{~cm}$ glass plate, leaving the red adhesive cover in place over one end of the double-sided tape. Using a dentist's pick, a dried disc of coffee berry borer artificial diet is placed on the glass plate. (c) The red adhesive cover is removed and an adult female is placed next to the diet. (d) The top glass plate is secured over the adhesive cover, and (e) foil tape is used to seal all four sides of the glass plates. 
5-6 days inside an oven set at $27^{\circ} \mathrm{C}$ (fig. la) until the diet had reached ca. 63\% moisture (from an original ca. $72 \%$ when poured), which is favourable for insect development. Moisture was measured using a Denver Instrument Model IR-50 moisture analyser (Denver Instrument, Bohemia, NY). Too much moisture in the diet will create condensation inside the diet sandwich, which results in insects permanently adhering to the moistened areas and eventually dying. Drying in the oven also allows for venting of gases in the diet that if not allowed to escape, could have a detrimental effect on the insects once they are sealed inside the two glass plates.

After testing various glass size dimensions, an optimal artificial diet sandwich size was used: a l-mmthick strip of double-sided Scotch ${ }^{\circledR}$ Extreme Mounting Tape (3M, St. Paul, MN) was adhered to the perimeter of one $3.8 \times 3.8 \mathrm{~cm}$ glass plate $(2.4 \mathrm{~mm}$ thick), temporarily leaving the red adhesive cover in place over one end of the double-sided tape (fig. lb). The dried diet discs were removed from the large glass plate using a dental pick, and one disc was placed on a $3.8 \times 3.8 \mathrm{~cm}$ glass plate (fig. $1 \mathrm{~b}$ ), followed by the placement of the desired number of insects (fig. lc), which had been reared on artificial diet. The two glass plates were joined together by removing the red plastic cover over the adhesive on the 1-mm-thick strip of double-sided tape and squeezing the plates together to achieve a good seal (fig. ld). The edges of the glass were then sealed with Nashua Multi-purpose HVAC Foil Tape (Berry Plastics Corporation, Franklin, KY) (fig. le) to prevent the insects from escaping through the mounting tape.

The sealed artificial diet sandwiches were placed in horizontal position inside a Percival Scientific E36L growth chamber (Percival Scientific, Inc., Perry, IA) set at $25^{\circ} \mathrm{C}$ and a dark photoperiod, that is the same conditions used for rearing the insects on artificial diet (Vega et al. 2011). For video recordings, diet sandwiches with different combinations of male and female insects were moved to another Percival Scientific E-36L growth chamber set at $25^{\circ} \mathrm{C}$, placed again in horizontal position and recorded for $1 \mathrm{~h}$ using a stereoscope and video recording equipment for large content image rendering (Baltimore Precision Instruments, Baltimore, MD), both installed inside the growth chamber. Lighting of the recording arena was performed with a dual-gooseneck Dolan-Jenner Ml-150 Fiber-Lite ${ }^{\circledR}$ Illuminator (Dolan-Jenner Industries, Boxborough, MA) and a Luxo 18743 Dimmable 80 LED High Output Ring Light (Luxo Corporation, Elmsford, NY), resulting in 6.8-7.2 klux.

\section{Results and Discussion}

One major advantage of the use of pre-dried artificial diet discs (as discussed above) in the diet sandwiches is that it allows using almost $100 \%$ of the diet sandwiches that are initiated. Occasionally, an insect will die after sealing the diet sandwiches, but overall, there are no problems with excessive moisture, which as we were developing the technique, caused high insect mortality due to insects becoming trapped in the moist areas of the glass. More importantly, the technique allows observing specific types of behaviour in $100 \%$ of the diet sandwiches with live insects, although if the focus of a study is to observe oviposition-related behaviour, it is important to note that there might not be oviposition in all of the diet sandwiches. For example, in an experiment using one female per diet sandwich with 29 replicates, oviposition had occurred in 12 of the diet sandwiches $(41 \%)$ at 15 days post-initiation, with a total of 40 eggs $(3.3 \pm 0.59 ;$ mean $\pm \mathrm{SE} ; \mathrm{n}=12)$ and six larvae $(0.54 \pm 0.20 ; \mathrm{n}=12)$. At 30 days post-initiation, oviposition had occurred in 14 of the diet sandwiches $(48 \%)$ for a total of 60 eggs $(4.3 \pm 1.15 ; \mathrm{n}=14)$ and 65 larvae $(4.6 \pm 1.11 ; \mathrm{n}=14)$, and none of the founder females had died. The low oviposition rate described above might have been due to low mating rates in the females used to initiate the experiment. The following life stages were recorded in the 18 diet sandwiches with oviposition (62\%) 41 days after initiation: 21 adult females $(1.2 \pm 0.51 ; \mathrm{n}=18)$, not including the founder female; 35 female pupae $(1.9 \pm 0.62 ; \mathrm{n}=18)$; five adult males $(0.3 \pm 0.13$; $\mathrm{n}=18)$; six male pupae $(0.3 \pm 0.14 ; \mathrm{n}=18)$; 91 larvae $(5.1 \pm 0.96 ; \mathrm{n}=18)$; and 95 eggs $(5.3 \pm 0.79$; $\mathrm{n}=18)$.

To determine whether insects placed in diet sandwiches could survive longer than 30 days, we recorded life stages present 53 days after initiating diet sandwiches in which two females and one male (taken from the laboratory population) were introduced into each of six diet sandwiches. We recorded 38 new female adults $(6.3 \pm 2.18)$, six new male adults $(1.0 \pm 0.36), 49$ female pupae $(8.2 \pm 0.65)$, four male pupae $(0.7 \pm 0.33), 78$ larvae $(13.0 \pm 3.85)$ and 34 eggs $(5.7 \pm 1.67)$, and all the founder females and the original males were still alive. Thus, the diet sandwiches are effective in maintaining insects alive, active and reproducing for almost 2 months, although the upper limit for survival (days) has not been determined.

The typical time from egg to adult in the field and in artificial diet depends on temperatures, with 
30-35 days not being uncommon (Vega et al. 2015). Based on data from various experiments conducted as part of this study (1), the time to first adult emergence ranged from 31-35 days, which indicates that the diet sandwich does not negatively influence developmental time, and (2) first batches of eggs are laid 6-7 days post-initiation of the experiments.

Another advantage of the diet sandwiches is that the thin diet disc allows us to observe the insects from both sides of the glass; thus, no insects are hidden inside galleries and are therefore observable. This is a clear advantage over other methodologies in which tubes are filled with artificial media and galleries are visible from the outside in only ca. $30 \%$ of the nests (Biedermann and Taborsky 2011). Hence, it might be worthwhile to test our setup with the various artificial diets that have been developed for other Scolytinae, like some fungusfarming ambrosia beetles, for example Xyleborini (French and Roeper 1972; Sivapalan and Shivanandarajah 1977; Roeper et al. 1980; Norris and Chu 1985; Biedermann et al. 2009; Mizuno and Kajimura 2009; Castrillo et al. 2012) and some phloemfeeding bark beetles such as Ips (Richeson et al. 1970; Simsek and Führer 1993; Mattanovich et al. 1999) and Scolytus spp. (Galford 1969).
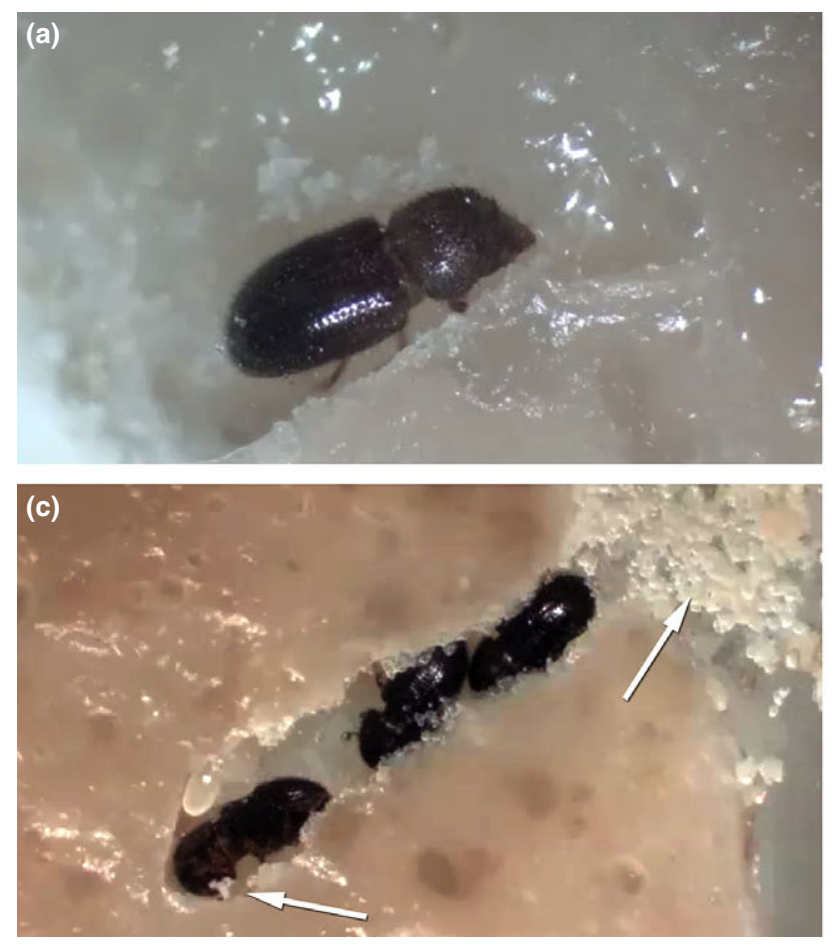
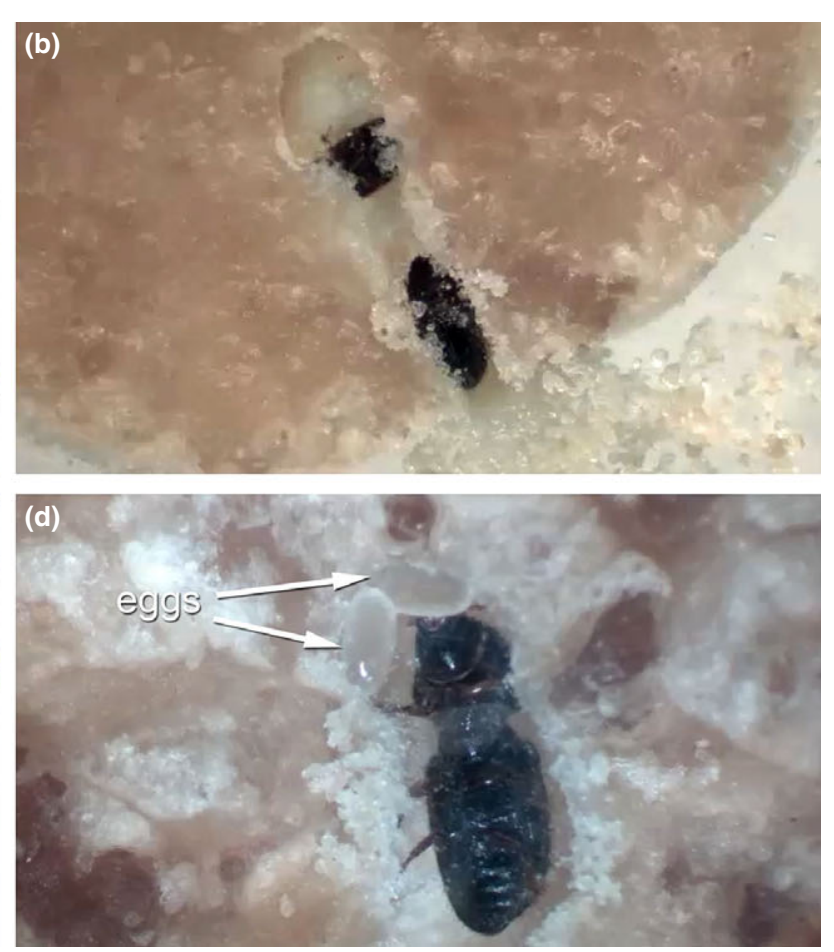

The artificial diet sandwiches have been useful to observe and record different types of behaviour in male and female adults and in immature stages, which are impossible to see under natural conditions, that is when the insect is inside the coffee berry. In addition to oviposition, we observed several putative social behaviours such as gallery construction (fig. 2a), gallery blocking by females (fig. 2b, c) and sanitation [i.e. shuffling of food (fig. 2c) and/or faeces combined with constant upkeep of the gallery]. Oviposition was followed by immediately using the legs to move the egg to the closed end of the tunnel (i.e. to the inside of the nest), with subsequent grooming involving apparent oral depositions over the egg (fig. 2d; Supplementary Video l: https://drive.google. com/open?id=0B-Edvo08NEoTdWJOakw0clpEY2c). Grooming of eggs has also been observed in cooperatively breeding ambrosia beetles in the tribe Xyleborini (Kingsolver and Norris 1977a,b; Biedermann and Taborsky 2011), but to the best of our knowledge, this is the first video recording of this behaviour. Scolytinae eggs are 'unusually large' (Kirkendall et al. 2015), as can be appreciated in Supplementary Video 1 for the coffee berry borer, whose eggs are ca. $0.70 \mathrm{~mm}$ long (Constantino et al. 2011). Based on a female length of 1.6-1.9 mm (Vega et al.

Fig. 2 Different types of coffee berry borer behaviour observed when using artificial diet sandwiches: (a) gallery construction; (b, c) gallery blocking by females; (c) sanitation, that is shuffling, movement of food (arrows); and (d) egg grooming. 
2015), eggs are $37-44 \%$ the length of the female body. Females have also been observed mating in the diet sandwiches, as well as grooming and moving larvae. We have also observed females pushing other females.

On nine occasions in which treatments consisted of one $(n=3)$, three $(n=1)$, four $(n=4)$ or six $(n=1)$ females per diet sandwich (replicates per treatment were 29, 8, 12 and 6, respectively), we noticed that eggs that had been accounted for ended up disappearing. The highest number of eggs disappearing was three. We ascribe this to cannibalism, based on (i) no increases in larval numbers, and on (ii) one observation of a female with her mouthparts in a half-eaten egg. Egg cannibalism has been reported for several non-carnivorous insects (Richardson et al. 2010), and to the best of our knowledge, it has only been reported once for bark beetles (Ips calligraphus; Wagner et al. 1987). On a few occasions, we observed an adult biting a larva, subsequently resulting in the formation of a necrotic area. These necrotic areas are also occasionally seen in larvae in our artificial diet population.

Gallery blocking and hygienic tasks such as shuffling of frass as well as grooming of eggs and larvae are signs of subsocial behaviour (the usual definition of subsociality is post-ovipositional parental care; Wilson 1971). Subsociality is relatively rare in insects, but common in some groups of beetles such as Passalidae, Scarabaeidae, Silphidae, Bostrichidae, Ciidae and Curculionidae (e.g. Scolytinae, Platypodinae, Cossoninae and Conoderinae) (Tallamy 1984; Halffter 1991;
Kirkendall et al. 2015). Here, we show that subsocial behaviours are not only restricted to phloem-feeding and fungus-farming Scolytinae, but are also present in seed feeders; the coffee berry borer shares many of the social behaviours that have been observed in other taxa (see table 1). At this point, we do not know whether larvae also contribute with cooperative tasks (i.e. nest hygiene), like in some other scolytines. Also it is unclear whether excavation of the gallery and cannibalism by the coffee berry borer are purely selfish behaviours or whether they also increase the fitness of the brood as a by-product. Cannibalism, for example, may serve the rapid elimination of diseased individuals, before pathogens can spread within the nest (Cremer et al. 2007). The grooming of eggs and larvae is present in ambrosia beetles of the tribe Xyleborini (Biedermann and Taborsky 2011), but has not been observed in any of the non-fungus-farming species. As in ambrosia beetles that need to protect their fungus cultures, nest sanitation, including grooming of others (i.e. allogrooming), might be important for protecting the nutritional substrate against microbial competitors in the coffee berry borer and possibly other seed-nesting species.

The use of artificial diet sandwiches should allow for a better understanding of the behaviour of the most important insect pest of coffee worldwide. Future studies will focus on (i) developing ethograms of observed behaviours in larvae, males and females and when different combinations of males and mated or unmated females are present in the same artificial

Table 1 Overview of Scolytinae social behaviours in relation to their mode of feeding and possible beneficial functions for the group. Behaviours exhibited by larvae (L), females (F) or males (M)

\begin{tabular}{|c|c|c|c|c|c|}
\hline \multirow[b]{2}{*}{ Behaviour } & \multirow[b]{2}{*}{ Definition } & \multirow[b]{2}{*}{ Possible social function } & \multicolumn{3}{|c|}{ Feeding mode of Scolytinae spp. } \\
\hline & & & Seed feeders ${ }^{1}$ & Phloem feeders ${ }^{2}$ & $\begin{array}{l}\text { Ambrosia } \\
\text { fungus feeders }{ }^{3}\end{array}$ \\
\hline Excavation & $\begin{array}{l}\text { Enlarging the nest which may } \\
\text { have a nutritional function. }\end{array}$ & Gallery extension & $L, F, M$ & $L, F, M$ & $L, F, M$ \\
\hline Fungus cropping & Grazing on fungus covering gallery walls. & Fungus tending & - & - & $F, M$ \\
\hline Balling & $\begin{array}{l}\text { Forming balls of frass by repeated } \\
\text { ventral body contractions. }\end{array}$ & Hygiene & $?$ & $\mathrm{~L}$ & $\mathrm{~L}$ \\
\hline Shuffling & $\begin{array}{l}\text { Moving food or frass with the body } \\
\text { (L) or the legs and elytra (F). }\end{array}$ & Hygiene & $\mathrm{F}$ & $L, F$ & $L, F$ \\
\hline Cannibalism & $\begin{array}{l}\text { Feeding on an egg, larva, pupa or } \\
\text { adult beetle that might be dead. }\end{array}$ & Hygiene & $\mathrm{F}$ & $\mathrm{F}, \mathrm{M}$ & $L, F, M$ \\
\hline Allogrooming & $\begin{array}{l}\text { Grooming an egg, larva, pupa or } \\
\text { adult beetle with mouthparts. }\end{array}$ & Brood care, hygiene & $\mathrm{F}$ & $?$ & $L, F, M$ \\
\hline Blocking & Plugging entrance tunnel with the body. & Protection & $\mathrm{F}$ & $F, M$ & $\mathrm{~F}$ \\
\hline
\end{tabular}

References: ${ }^{1}$ Hypothenemus hampei (this study) and Coccotrypes spp. (Herfs 1950, 1959); ${ }^{2}$ Dendroctonus spp. (Reid 1958; Deneubourg et al. 1990) and Ips spp. (Wichmann 1967; Kirkendall et al. 2015); ${ }^{3}$ Xyleborus spp. (Kingsolver and Norris 1977a,b; Biedermann et al. 2011; Biedermann 2012), Xylosandrus germanus (Bischoff 2004) and Xyleborinus saxesenii (Biedermann and Taborsky 2011). 
diet sandwich; (ii) how individuals react towards placement of microbial pathogens (e.g. Beauveria bassiana) inside the artificial diet sandwich; (iii) potential delayed dispersal of adult offspring from their mother's nest and their engagement in cooperative tasks and breeding; and (iv) egg survival after removing mothers from the nest. We hope these studies will allow us to observe other types of behaviour such as male and/or female competition or cooperation, larval behaviour, cannibalism and social immunity.

\section{Acknowledgements}

Marian M. Rodríguez-Soto was supported by the Hispanic-Serving Institutions Education Grants Program at the United States Department of Agriculture National Institutes of Food and Agriculture (NIFA). Peter Biedermann was supported by a Marie Curie Intra-European Fellowship (IEF) (Project Number 626279). Special thanks to Matthew Richardson, Roger Beaver and Lawrence Kirkendall for comments on egg cannibalism. We thank Chris Pooley (USDA, ARS) for preparing the figures.

\section{References}

Aflitto NC, Hofstetter RW, McGuire R, Dunn DD, Potter KA, 2014. Technique for studying arthropod and microbial communities within tree tissues. J Vis Exp, 93, e50793.

Beanlands GE, 1966. A laboratory-rearing method for observing adult bark beetles and their developing broods. Can Entomol, 98, 412-414.

Bedard WD, 1933. The number of larval instars and the approximate length of the larval stadia of Dendroctonus pseudotsugae Hopk., with a method for their determination in relation to other bark beetles. J Econ Entomol, 26, 1128-1134.

Biedermann PHW, 2012. The evolution of cooperation in ambrosia beetles. PhD thesis, University of Bern, Switzerland.

Biedermann PHW, Taborsky M, 2011. Larval helpers and age polyethism in ambrosia beetles. Proc Natl Acad Sci USA, 108, 17064-17069.

Biedermann PHW, Klepzig KD, Taborsky M, 2009. Fungus cultivation by ambrosia beetles: behavior and laboratory breeding success in three xyleborine species. Environ Entomol, 38, 1096-1105.

Biedermann PHW, Klepzig KD, Taborsky M, 2011. Costs of delayed dispersal and alloparental care in the funguscultivating ambrosia beetle Xyleborus affinis Eichhoff (Scolytinae: Curculionidae). Behav Ecol Sociobiol, 65, 1753-1761.
Bischoff LL, 2004. The social structure of the haplodiploid bark beetle, Xylosandrus germanus. MSc thesis, University of Bern, Switzerland.

Cardoza YJ, Klepzig KD, Raffa KF, 2006. Bacteria in oral secretions of an endophytic insect inhibit antagonistic fungi. Ecol Entomol, 31, 636-645.

Castrillo LA, Griggs MH, Vandenberg JD, 2012. Brood production by Xylosandrus germanus (Coleoptera: Curculionidae) and growth of its fungal symbiont on artificial diet based on sawdust of different tree species. Environ Entomol, 41, 822-827.

Constantino LM, Navarro L, Berrio A, Acevedo FE, Rubio D, Benavides P, 2011 . Aspectos biológicos, morfológicos y genéticos de Hypothenemus obscurus e Hypothenemus hampei (Coleoptera: Curculionidae: Scolytinae). Rev Colomb Entomol, 37, 173-182.

Cremer S, Armitage SAO, Schmid-Hempel P, 2007. Social immunity. Curr Biol, 17, R693-R702.

Deneubourg JL, Grégoire J-C, LeFort E, 1990. Kinetics of larval gregarious behaviour in the bark beele Dendroctonus micans (Coleoptera: Scolytidae). J Insect Behav, 3, 169-182.

French JRJ, Roeper RA, 1972. In vitro culture of the ambrosia beetle Xyleborus dispar (Coleoptera: Scolytidae) with its symbiotic fungus, Ambrosiella hartigii. Ann Entomol Soc Am, 65, 719-721.

Galford JR, 1969. A larval and ovipositional medium for the smaller European elm bark beetle. J Econ Entomol, 62, 1166-1168.

Grosman DM, Salom SM, Payne TL, 1992. Laboratory study of conspecific avoidance by host-colonizing Dendroctonus frontalis Zimm. (Coleoptera: Scolytidae). J Insect Behav, 5, 263-271.

Halffter G, 1991. Feeding, bisexual cooperation and subsocial behavior in three groups of Coleoptera. In: Advances in coleopterology. Ed. by Zunino M, Bellés M, Blas M, European Association of Coleopterology, Barcelona, 281-295.

Herfs A, 1950. Studien an dem Steinnußborkenkäfer, Coccotrypes tanganus Eggers. Höfchen-Briefe für Wissenschaft und Praxis, 2, 22-49.

Herfs A, 1959. Über den Steinnußborkenkäfer Coccotrypes dactyliperda F. Anz Schädlingskunde, 32, 1-4.

Hopping GR, 1961. Techniques for rearing Ips De Geer (Coleoptera: Scolytidae). Can Entomol, 93, 1050-1053.

Kingsolver JG, Norris DM, 1977a. The interaction of Xyleborus ferrugineus (Fabr.) (Coleoptera: Scolytidae) behavior and initial reproduction in relation to its symbiotic fungi. Ann Entomol Soc Am, 70, 1-4.

Kingsolver JG, Norris DM, 1977b. The interaction of the female ambrosia beetle, Xyleborus ferrugineus (Coleoptera: Scolytidae), with her eggs in relation to the morphology of the gallery system. Entomol Exp Appl, 21, 9-13. 
Kinn DN, Miller MC, 1981. A phloem sandwich unit for observing bark beetles, associated predators, and parasites. Southern Forest Experiment Station Research Note SO-269, 3 pp.

Kirkendall LR, Kent DS, Raffa KF, 1997. Interactions among males, females and offspring in bark and ambrosia beetles: the significance of living in tunnels for the evolution of social behavior. In: The evolution of social behavior in insects and arachnids. Ed. by Choe JC, Crespi BJ, Cambridge University Press, Cambridge, 181-215.

Kirkendall LR, Biedermann PHW, Jordal BH, 2015. Evolution and diversity of bark and ambrosia beetles. In: Bark beetles: biology and ecology of native and invasive species. Ed. by Vega FE, Hofstetter RW, Academic Press, San, Diego, 85-156.

Mattanovich J, Ehrenhöfer M, Vavra C, Führer E, 1999. Zur Weiterentwicklung eines halbsynthetischen Närhmediums für Ips typographus L. Anz Schädlingskunde, 72, 49-51.

Mizuno T, Kajimura H, 2009. Effects of ingredients and structure of semi-artificial diet on the reproduction of an ambrosia beetle, Xyleborus pfeili (Ratzeburg) (Coleoptera: Curculionidae: Scolytinae). Appl Entomol Zool, 44, 363-370.

Norris DM, Chu H-M, 1985. Xyleborus ferrugineus. In: Handbook of insect rearing, Vol. I. Ed. by Singh P, Moore RF, Elsevier, Amsterdam, 303-315.

Reid RW, 1958. The behaviour of the mountain pine beetle, Dendroctonus monticolae Hopk., during mating, egg laying, and gallery construction. Can Entomol, 90, 505-509.

Richardson ML, Mitchell RF, Reagel PF, Hanks LM, 2010. Causes and consequences of cannibalism in noncarnivorous insects. Annu Rev Entomol, 55, 39-53.

Richeson JS, Wilkinson RC, Nation JL, 1970. Development of Ips calligraphus on foliage-based diets. J Econ Entomol, 63, 1797-1799.

Roeper R, Treeful LM, O'Brien KM, Foote RA, Bunce MA, 1980. Life history of the ambrosia beetle Xyleborus affinis (Coleoptera: Scolytidae) from in vitro culture. Great Lakes Entomol, 13, 141-144.
Salom SM, Stephen FM, Thompson LC, 1986. Development of Hylobius pales (Herbst) immatures in two types of phloem media. J Entomol Sci, 21, 43-51.

Silva WD, Mascarin GM, Romagnoli EM, Bento JMS, 2012. Mating behavior of the coffee berry borer, Hypothenemus hampei (Ferrari) (Coleoptera: Curculionidae: Scolytinae). J Insect Behav, 25, 408-417.

Simsek Z, Führer E, 1993. Künstliches Nähr- und Brutmedium für Ips typographus L. (Col., Scolytidae). J Appl Entomol, 116, 432-439.

Sivapalan P, Shivanandarajah V, 1977. Diets for rearing the ambrosia beetle of tea, Xyleborus fornicatus (Coleoptera: Scolytidae), in vitro. Entomol Exp Appl, 21, 1-8.

Tallamy DW, 1984. Insect parental care. BioScience, 34, 20-24.

Taylor AD, Hayes JL, Roton L, Moser JC, 1992. A phloem sandwich allowing attack and colonization by bark beetles (Coleoptera: Scolytidae) and associates. J Entomol Sci, 27, 311-316.

Ueda A, 1997. Brood development of an inbreeding spermatophagous scolytid beetle, Coccotrypes graniceps (Eichhoff) (Coleoptera: Scolytidae). Jpn J Entomol, 65, 677-687.

Vega FE, Kramer M, Jaramillo J, 2011. Increasing coffee berry borer (Coleoptera: Curculionidae: Scolytinae) female density in artificial diet decreases fecundity. J Econ Entomol, 104, 87-93.

Vega FE, Infante F, Johnson AJ, 2015. The genus Hypothenemus, with emphasis on $H$. hampei, the coffee berry borer. In: Bark beetles: biology and ecology of native and invasive species. Ed. by Vega FE, Hofstetter RW, Academic Press, San Diego, 427-494.

Wagner TL, Fargo WS, Flam RO, Coulson RN, Pulley PE, 1987. Development and mortality of Ips calligraphus (Coleoptera: Scolytidae) at constant temperatures. Environ Entomol, 16, 484-496.

Wichmann HE, 1967. Die Wirkungsbreite des Ausstoßreflexes bei Borkenkäfern. Anz Schädlingskunde, 40, 184-187.

Wilson EO, 1971. The insect societies. Belknap Press of Harvard University, Massachusetts. 